\title{
Effectiveness of Transactional Analysis Group Training on Reduction of Prisoners' Aggression
}

\author{
Iman Lashani \\ Msc Staudent in General Psycholgy, Universy of Sistan and Baluchestan, Zahedan, Iran \\ za.karimi25@yahoo.com \\ Mehrdad Mazaheri \\ PhD, Associate Professor, Ferdowsi University of Mashhad \\ University of Sistan and Bluchestan Corresponding Author; M.Mazaheri@um.ac.ir
}

Doi:10.5901/mjss.2016.v7n4s2p219

Abstract

The main aim of current study was to survey on the effectiveness of transactional analysis group training on the prisoners' aggression reduction. The 24 voulentry prisoners (Experimental Group $=12$, Control Group $=12$ ) were selected using available sampling method and has been observed objectively as well as been scored using the Spielberge Aggressive Questionnare. The experimental group was trained under the transactional analysis training for 12 sessions. Our results indicated a significant effect of the transactional analysis training on the on the prisoners aggression decreasing.

Keywords: Transactional analysis training, Aggression, Prisoners

\section{Introduction}

A review of research shows that aggression is among the common behavior problems insofar as in the US, nearly a quarter of the population somehow experience this behavior during their life (Department of Health, 2001). Studies also indicate that the prevalence of this disorder among samples of convicted and imprisoned individuals are much higher than other people (Bickel \& Campbell, 2002). Aggression is generally arises due to failure to achieve the goal or inappropriate behaviors such as insults, trauma or reasonless fear. Children generally reflect aggression due to negligence or failure to perform duties. In adolescence, the most important source of aggression is attributed to social limitations and factors, and in adulthood the origin of aggression is disapproval, exclusion, exploitation and humiliation (Strickland, 2001). Mac Shaun (1989) indicates that patients with mental problems and illnesses, attack staff and other patients 5 times more than other patients do. A review of the figures demonstrates the need to create an atmosphere in prisons and detention centers based on which prisoners receive appropriate individual or group treatments. Rehabilitation and emphasizing psychological rehabilitation techniques on anger management for patients (as a psychologicaleducational intervention), especially for those who have cognitive deficits and psychiatric disorders, are very useful and effective (Taylor \& Novaco, 2005). The effectiveness of anger control methods is approved in several studies; for example, Ariland (2004), in a study conducted on the efficacy of short-term anger management programs among adolescent prisoners, found that the experimental group patients who received anger management skills training had a better psychological status compared to the control group patients and were able to control their anger. Among the various training methods that have different applications in various contexts of psychoanalysis is Eric Berne's transactional analysis (henceforward TA). The TA view is a system of psychotherapy used in the treatment of psychiatric disorders, from daily problems to very deep psychosis. Concepts such as the ego-state (parent-adult-child) model, interaction, caress, draft of life, mental game, independence and self-obey is used in this theory (Stewart \& Jones, 2007). Chapman (2007) defines TA as a type of social psychology that aims to improve communication. In this theory attempts are made to move people to reach a level of growth by which they can solve their own problems (The International Transactional Analysis Association, 2008). TA is used as a method for success, grow, and help people in life, work and personal growth (Davidson, 2007). The TA method is a rational approach that assists an individual to analyze and understand his/her own behavior as well as to acquire knowledge and take responsibility, according to what is happening in the present time (Stewart \& Jones, 2007). This is one of the most palpable theories of modern psychology which is 
performed mostly as a model of interpersonal communication. It is also a very common method of treatment (Tudor, 2002).

The purpose of TA is to release the adult ego-state from the harmful effects and the parent ego-state and the child ego-state, thereby, creates the desired behavioral changes. In other words, this approach seeks to achieve one's selfknowledge to know how to act in the face of the environment (Shafiabadi, 2006). According to Berns, steps of behavior change include: the elimination of inappropriate behavior, psychological discharge, description of and clarifying the communication methods and new orientation (Shafiabadi, \& Nasseri, 2006). TA group training, in a secure and supportive environment, allows clients to explore the issues and implications of ego. Addressing the issues and concepts related to ego, leads to insight, self-knowledge, breaking the resistance and ultimately treatment of the disorder symptoms. Since many psychologists and experts attribute aggressive behaviors to a lack of interpersonal communication skills, TA can reduce aggressive behaviors using techniques such as increasing social and group interactions and extending interpersonal experiences.

Changes in cognitive insight, consciousness levels, social skills training, deepening and broadening individual experiences, understanding strengths and weaknesses, and creating emotional and cognitive integration are among the reasons of improvement (Seghati, Shafiabadi \& Sowdaei, 2009). Several studies have shown that TA-based interventions reduce marital conflict (Hayatbakhsh, Shafiabadi \& Sanaee Zaker, 2010). Additionally, according to Shafiabadi and Nasseri (2001), TA seems to be a response to aggression, because this method is a means of self-knowledge and learning how to communicate with others. Cassico (2006) believes that training clients how to interact using TA can help them, in a short time, to improve communication and increase the efficiency of family members in different situations. Lawrence (2007) suggested that adoption of TA can enhance information about methods of interpersonal relationships and thereby increase more effective communication.

According to the above mentioned issues, the main hypothesis of the present study is:

- Transactional analysis training has an effect on prisoners' aggression.

\section{Methods}

The study population included all prisoners of the city of Doroud during .... The sample consisted of 24 prisoners residing in Doroud which were selected through applying availability sampling method on the basis of objective observations and scores on the Spielberger State-Trait Anger Expression Inventory. The participants were randomly divided into two groups of experimental $(N=12)$ and control $(N=12)$. The design was pretest-posttest with control group. The State-Trait Anger Expression Inventory (STAXI-2SS) was used for data collection. The questionnaire consists of 57 items including six scales, five subscales and an indicator for expression of anger which provides an overall level of anger control and expression. Analysis of covariance was used to test the hypothesis and to investigate the effect of TA on prisoners' aggression reduction.

\section{Procedure}

Subjects of the experimental group received 12 sessions of training and counseling with TA concepts and principles. Session I: Discussing the method, aggression and its consequences on an individual's physical and mental state and social interactions. Session II: Reviewing the previous session and discussing the types of aggression. Session III: Reviewing the previous session and discussing natural, adapted, and child ego, and children rebellious ego. Session IV: Reviewing the previous session and discussing parent ego, types of supportive, controlling, reproaching and feeding parents. Session V: Reviewing the previous session and discussing adult of personality, planning the ego states. Session $\mathrm{Vl}$ : Reviewing the previous session and discussing personality disease from the perspective of TA, rejection of dominancy, opening the concept of hosting. Session VII: Reviewing the previous session and discussing the status of life, a brief description of the relationship and communication units. Session VIII: Assessment of types of parallel, crossover and relationships. Session IX: Reviewing the previous session and discussing the Punisher triangle. Session X: Reviewing the previous session and discussing the damaged, savior and punisher character. Session XI: Reviewing the previous session and discussing how to establish a healthy and fruitful relationship based on TA and that in a healthy relationship a belief to the well-being of both individuals is necessary. Session XII: Reviewing the previous session, methods used in everyday situations and end of sessions. 


\section{Findings}

Table 1: Some descriptive statistics for aggression sub-scales

\begin{tabular}{|l|l|c|c|}
\hline \multicolumn{1}{|c|}{ Sub Scales } & Stage & $\boldsymbol{M}$ & SD \\
\hline \multirow{3}{*}{ Angry State } & Pre-test & $46 / 958$ & $4 / 685$ \\
\cline { 2 - 4 } & Post-test & $33 / 875$ & $6 / 654$ \\
\cline { 2 - 4 } & Follow up & $33 / 125$ & $7 / 415$ \\
\hline \multirow{3}{*}{ Angry Trait } & Pre-test & $27 / 833$ & $4 / 724$ \\
\cline { 2 - 4 } & Post-test & $24 / 791$ & $3 / 092$ \\
\cline { 2 - 4 } & Follow up & $24 / 916$ & $3 / 386$ \\
\hline \multirow{3}{*}{ Angry Projection } & Pre-test & $21 / 125$ & $2 / 401$ \\
\cline { 2 - 4 } & Post-test & $17 / 125$ & $3 / 340$ \\
\cline { 2 - 4 } & Follow up & $16 / 899$ & $2 / 963$ \\
\hline \multirow{3}{*}{ Angry Projection Control } & Pre-test & $19 / 791$ & $19 / 791$ \\
\cline { 2 - 4 } & Post-test & $17 / 984$ & $17 / 984$ \\
\cline { 2 - 4 } & Follow up & $18 / 026$ & $18 / 026$ \\
\hline \multirow{3}{*}{ Angry Introjection Control } & Pre-test & $18 / 250$ & $18 / 250$ \\
\cline { 2 - 4 } & Post-test & $16 / 541$ & $16 / 541$ \\
\cline { 2 - 4 } & Follow up & $16 / 001$ & $16 / 001$ \\
\hline & Pre-test & $21 / 075$ & $21 / 075$ \\
\cline { 2 - 4 } & Post-test & $17 / 721$ & $17 / 721$ \\
\cline { 2 - 4 } & Follow up & $18 / 129$ & $18 / 129$ \\
\hline
\end{tabular}

As seen in Table 1, all aggression sub-scales mean scores used to show a decreasing in pest-test compared with pretest stage. In order to find how transactional analysis training caused to the aggression reduction, an analysis of covariance (ANCOVA) was used and the results are presented in Table 2.

In order to test the homogeneity-of-regression (slope) assumption, the Levene's Test of Equality of Error Variance was used and the results indicated that the underlying assumption of homogeneity of variance for the one-way ANCOVA has been met, $F(1,23)=0.722, p>0.1$.

Table 2: Tests of Between-Subjects Effects

Dependent variable: Post-test aggression sub-scales scores

\begin{tabular}{|l|c|c|c|c|c|c|c|}
\hline Sub-scales & Source & Type III Sum of Squares & df & Mean Square & F & Sig. & Eta Square \\
\hline Angry State & Group & $38 / 098$ & 1 & $38 / 098$ & $11 / 367$ & $0 / 001$ & $0 / 387$ \\
\hline Angry Trait & Group & $31 / 994$ & 1 & $31 / 994$ & $6 / 623$ & $0 / 001$ & $0 / 269$ \\
\hline Angry Projection & Group & $62 / 031$ & 1 & $62 / 031$ & $6 / 494$ & $0 / 001$ & $0 / 265$ \\
\hline Angry Introjection & Group & $43 / 677$ & 1 & $43 / 677$ & $5 / 579$ & $0 / 001$ & $0 / 237$ \\
\hline Angry Projection Control & Group & $59 / 40$ & 1 & $59 / 40$ & $7 / 391$ & $0 / 001$ & $0 / 291$ \\
\hline Angry Introjection Control & Group & $58 / 048$ & 1 & $58 / 048$ & $7 / 903$ & $0 / 001$ & $0 / 305$ \\
\hline
\end{tabular}

As Table 2 shows, the transactional analysis training used to decreasing prisoners aggression for all aggression subscales. In the other word a significant difference on the aggression mean rating can be seen between pre-test and posttest measures Table 2).

The same analysis has been done for results obtained from follow up study to compare two studied groups (with and without the transactional analysis training) (Table 3).

Table 3: Tests of Between-Subjects Effects

Dependent variable: Follow-up aggression sub-scales scores

\begin{tabular}{|l|c|c|c|c|c|c|c|}
\hline Sub-scales & Source & Type III Sum of Squares & df & Mean Square & F & Sig. & Eta Square \\
\hline Angry State & Group & $41 / 210$ & 1 & $41 / 210$ & $9 / 277$ & $0 / 001$ & $0 / 572$ \\
\hline Angry Trait & Group & $34 / 343$ & 1 & $34 / 343$ & $5 / 471$ & $0 / 029$ & $0 / 207$ \\
\hline Angry Projection & Group & $75 / 031$ & 1 & $75 / 031$ & $12 / 586$ & $0 / 002$ & $0 / 265$ \\
\hline Angry Introjection & Group & $64 / 594$ & 1 & $64 / 594$ & $11 / 469$ & $0 / 003$ & $0 / 353$ \\
\hline
\end{tabular}




\begin{tabular}{|l|l|l|l|l|l|l|l|}
\hline Angry Projection Control & Group & $72 / 532$ & 1 & $72 / 532$ & $7 / 361$ & $0 / 013$ & $0 / 260$ \\
\hline Angry Introjection Control & Group & $85 / 548$ & 1 & $85 / 548$ & $10 / 114$ & $0 / 005$ & $0 / 325$ \\
\hline
\end{tabular}

As seen in Table 3, the results obtained from follow up study shows a significant effect of the transactional analysis training to the prisoners aggression reduction.

\section{Conclusion}

The aim of this study was to evaluate the effectiveness of Eric Berne's transactional analysis training on aggression reduction among prisoners. According to the results (Tables 2 and 3), TA is an appropriate and effective method to reduce aggression of prisoners. These findings are consistent with other research (Hayatbakhsh, Shafiabadi \& Sanaee Zaker, 2010, Shafiabadi \& Nasseri, 2011; Seghati, Shafiabadi, Sowdaei, 2009) suggesting the effectiveness of TA in improving communication skills. TA is in fact a global idea to communicate in a variety of cultures.

This theory attempts to move people to reach a level of growth by which they can solve their own problems. TA can reduce aggressive behaviors using techniques such as increasing social and group interactions and extending interpersonal experiences. TA is a response to aggression, since it provides a method for self-knowledge and learning how to communicate with others (Tudor, 2002; Seghati, Shafiabadi \& Sowdaei, 2009; Cassico, 2006; Lawrence, 2007). In fact, TA is a rational approach that assists an individual to analyze and understand his/her own behaviors as well as to acquire knowledge and take responsibility, according to what is happening in the present time (Stewart \& Jones, 2007).

Overall, it could be argued that interaction training using TA can help clients, in a short time, to improve their communications (Cassico, 2006) and increase the efficiency of family members in different situations (Lawrence, 2007) and as a result reduce aggression.

\section{References}

Bickel R, \& Campbell, A .(2002). Mental health of adolescents in custody: The use of the adolescentpsychopathology scale in a tasmanian context. Austral N Zealand J Psychiat;36:603-9.

Chapman, A. (2007). Eric Berne's transactional analysis parent adult child model, theory and history article [On-line]. Available: http: I/www. businessballs. com/transact. html

Davidson, C. (2007). Transactional analysis, Eric Berne, theory examples, articles, diagrams, parent, adult, child [On-line]. Available: http: //businessballs. Com/transaction analysis.html

Department of Health.(2001). Major mental health publicity chomping to reduce discrimination.London: Department of Health.

Harris TA, Harris AB. Staying ok, 5th ed. New York: Morrow - avon, 2004:pp: 5-6.

Kazeko, F. (2006).Effects of transactional analysis training on seventh grade students. Transaction Analysis Journal, 22-29

Lawrence, L. (2007). Applying transactional analysis and personality assessment to improve patient counseling and communication skills.Journal of Pharmaceutical Education. 77, 1-5.

Ireland, J,L. (2004). Anger management therapy with young male offenders. Anger Beh; 30(2):174-85.

Mc Shane, MD. (1989). The bus stop revisited: Discipline and psychiatric patients in prison. JournalPsychiat Law;17:413-33.

Shafieabadi A, NaseriGh. Consulation Theories and psychotherapy, 12 Ed Tehran: University Publication Center. 2006: pp: 216-42. \{Persian\}.

Stewart I. Joines V. A new Introduction to Transactional Analysis, 7 th ed. Carolina: Lifeespan, 2007: pp:22 -8.

Strickland, B. (2001). The GALE Encyclopedia of Psychology.2ed edition, Gate Group, USA.

Taylor, J.L., \&Novaco, R.W. (2005). Anger treatment for people with developmental Disabilities:A theory, evidence and manual based approach. John Wiley \& Sons, Ltd.

Tudor, K. (2002). Transactional analysis supervision or supervision analysis Transactional? Transactional analysis Journal, 32, 39-55.

The International Transactional Analysis Association (2008). The training \& certification council of transactional analysis, Inc. [On-line]. Available: http: //www. ITAA-net.Org/index.html 